\title{
The Creative Well: Fostering Creativity for a Market-Driven Industry
}

\author{
Michael Pope, S. Lee, \\ Fashion and Technology Degree, Kwantlen Polytechnic University
}

\begin{abstract}
In this paper we discuss ongoing classroombased research promoting realistic ways of maintaining creativity within the demands of the fashion industry. The project fosters and replenishes the creative spirit, helping students realize the importance of maintaining inventiveness Fashion design carries an aura of spontaneous creativity, yet the business of fashion is less about abstracted creativity and innovation and more the needs of the marketplace. Maintaining, generating, and developing creativity is a common challenge for designers, where the initial stage of design may be examining last season's spreadsheets Students faced with the reality of the business of fashion frequently wonder how creative vision can work within industry. Helping fashion students learn the pragmatic demands and challenges of the workplace is the only responsible option if educators are to prepare them for rewarding careers, yet students may feel overwhelmed or out of touch with the creativity essential to a rewarding practice as a result. Our "Creative Well" project presents an innovative approach to nurturing the creative spirit.
\end{abstract}

\section{Introduction}

Pause for a moment. How does creativity play a part in your work?

In a discipline such as fashion design, which is both innovation and business, the challenge of the balance between creativity and work is ongoing. Teaching fashion studies, like many disciplines, requires a great deal of time spent on the necessary rules, be they of costing or consumer preferences. Eventually students may feel a sense of loss or creative drought.

Educators face a profound dilemma as they struggle to foster inventiveness while teaching core concepts and practices. In the project we discuss, The Creative Well, we strive to find water in the desert and to help students find ways to replenish their inspiration and drive and to do so in a way they can develop within their careers. The results are impressive. Students redefine themselves as creative and thinking beings, create novel projects that speak to others, and leave with a renewed sense of the importance of creativity, and creative process, in their lives. This carries into their careers and builds the traditional personal growth goals of liberal education. Both teacher and student benefit.

We are in a time of great interest in the nature of creativity with changing perceptions of what it might be, and how it might be fostered within a life, a business and a classroom. Although our focus is fashion, much of what we discovered through this project is transferable to other disciplines.

In compiling research for this paper, the sheer amount of source material indicated multiple directions for the study of creativity - much of it geared toward industries or disciplines not often associated with creativity. This was not surprising, but what we did discover was any discussion of creativity was closely linked to the concept of happiness. That is to say, for effective fostering of creativity there must be for the individual a sense of well-being derived from feeling useful. In context to a classroom setting, encouraging creative freedom and development is connected to Gauntlett's premise that no society can flourish without some sense of shared purpose.

Instructors must continually evaluate criteria for any project from several perspectives; learning objectives, student learning outcomes, relevance to industry applications, etc. For the Creative Well we have discovered there are secondary outcomes resulting from the very nature of making creative associations. These are compounded in a way that addresses what Sternberg identifies as the four major approaches to creativity, specifically the creative environment (the classroom), the creative person (the student) the creative process (any method of exploring solutions) and the creative product ( the unknown " $X$ " result of the process). The importance of each approach fluctuates for each student as the project evolves. This is twofold in benefits; the student feels a sense of autonomy over their process, and the work of the entire creative community remains organic, allowing the project to remain fluid semester after semester.

We begin with a brief description of the context of the project and its key features and goals. We discuss student response and our ongoing research, and end with an analysis of successes and challenges. Throughout, we bring in the voices of academics considering creativity and students reflecting on this 
project. One recent student gives a clear sense of the 'features and goals' of the Creative Well.

"The Creative Well not only gave me the opportunity to reconnect with influences that have fueled my need to create, but allowed me to experiment with forms of communicating in a way that would relate to others. The fact that we got to step away from fashion, in a typical sense, and view, try, and discuss the possibilities of art and creativity was enriching and inspiring.

The process let the product come organically, in a kind of network that didn't fully take shape until the end; that state of constant experimentation and reflection was perhaps the most challenging and rewarding aspect of the project.

As an aspiring designer, one of the things that I'll take from the Creative Well is the ability to pull from a broader, more informed perspective, make connections and bring them back into a garment, making the work much more complex and meaningful.”

\section{The Creative Well context}

The Fashion and Technology Program, at Kwantlen Polytechnic University, is a four-year degree with an exceptionally high employment rate, largely due to its intense and industry focused curriculum. Great emphasis is placed on wearable and saleable fashion. Some electives build a traditional liberal education and to some extent these goals-understanding context, tolerance, critical inquiry-are promoted within fashion courses.

Students entering the program are young and, while committed and curious, naïve about the challenges of a creative discipline. Consequently, by spring of $2^{\text {nd }}$ year they are sorely tested in their original concepts of the role of a fashion designer and are often questioning their direction. While each semester features projects with creative components, by this time students, while greatly valuing their industry knowledge and skills, often feel drained and at a loss for innovation. For many, the core motivation of making sense of the world through the sensory experience of textiles and the necessary social interaction of clothing is increasingly buried under a spreadsheet.

In the spring semester of Year Two, students engage in two industry-based projects, with the Creative Well project ending the semester. The Creative Well helps them to find that core love of creating again and also, and as importantly, leads to new conceptions of self in the world that aid them in their futures.

The project starts, as all our design projects do, with an introductory design brief. We begin the Creative Well with a story and a big theme. Gratitude, service, the journey are past examples. From the beginning, we build on our creative community through shared story, shared experience and, often, shared food.

We present students with a challenge following the norms of design problems. The challenge is intentionally ill defined, open-ended and eludes immediate understanding. "Follow our guides for thought and action in the next four classes, then create a holistic " $X$ " that communicates meaningfully to other people." When students ask, "What is the end result?" teachers answer, "We don't know yet."

The project is set up to take advantage of Sawyer's components of everyday creativity. We enable people to work in collaborative and improvisational ways, with variable results. Process and communal knowledge are key. While we provide a loose structure, the project defies traditional methods of planning and revising. (In this, it sounds like many workdays.)

Six classes follow. The first four feature specific exercises, all with the focus on divergent thought and action. In this stage students engage with research we provide (although they soon turn the tables) and write responses to various TED talks, which can be postcards or poems, short commentaries or cartoons. For example, the initial TED talks critically examine the nature of educating for creativity and of the socio-political role of art. They create two drawings a week, posted during class for viewing only.

Work created in the first four classes may or may not inspire the students' final response. While the required activities cover many of Howard Garner's well-known multiple intelligences, students are free to create their holistic work in any way they choose.

In the first class, students embroider for four hours, after studying contemporary directions in this old craft. This is a new experience for most and is heightened by the use of unconventional organic material such as moss or orange peels as inspiration and sometimes medium. Exploration is stressed over excellence.

As this project has continually developed in a culture of exploration and of the unknown, (by the teachers as well as the students) validation for this first class has become evident. Embroidery, by nature, requires the participants to mentally and physically slow down. The students in this program are by this time accustomed to working on multiple projects with multiple deadlines simultaneously. Both in and outside the classroom, this generation of students has more immediate access to information than any group preceding them. Consequently, they have been found to be distracted by over-stimulation. To physically force them to slow down prepares them for the psychological trigger preceding a creative breakthrough. According to Sternberg, current studies of creativity often acknowledge slowing the brain and the body enhances the process. 
Before the second class students prepare by exploring outsider art. In this drawing class, they work with models whose bodies, clothing and actions are unexpected. Chosen for difference and dynamic interaction, a model may be over seventy years old and over two hundred pounds, or prone to wearing six tutus at once, some as headpieces. Models may spend the whole class working to a theme from Greek myth. In all these classes, teachers set up the space but do not "help" with any perceived drawing challenges.

We have witnessed major breakthroughs for students during this class, whether based on a dissembling of current biases toward body image, or an acknowledgement of a serious creative community, or the idea that any manner of observing and recording is valid. One drawing session resulted in a circle of students sitting on the floor giving each other massages while the model took a break. Another instance saw the students go outside the next afternoon to continue drawing, but this time in the parking lot to create a massive mural with brightly colored chalk.

Prior to the third class, creative painting, students study the work of Vic Muniz, who has used sugar, chocolate and cloud vapor as media. In this class a very tightly wound student found freedom as a canvas when she suggested others quite literally paint her.

In the fourth and final directed class we study land artist Andy Goldsworthy in the film "Rivers and Tides". At the end, students go into nature and create their own land art.

The fifth and sixth classes provide students with time to develop their holistic responses and then present them in a student-led, gallery-style presentation.

The timeline for the project includes both exploration and incubation. It was not until research for this paper began that we discovered what began as a pedagogical solution for creative barriers is analogous to scholarly concepts of discussing creative education. Psychologist Keith Sawyer describes 5 stages of the creative process in a way which systematically harmonizes with this project. The following 5 descriptors are Sawyers definitions; the context is the project.

Preparation: This stage allows students to discover, explore, work hard and continually discuss the early stages of the process. For the Creative Well, this stage is often called "scratching".

Time Off: This is Sawyer's terminology, something we encourage as either reflection or serving the creative community. Students often record reflections in a state of solitude, or conversely, to communally participate in sharing food. We see students at this stage examine context and begin to combine creative activities. Time off occurs when the participants start to regard constraints as creative opportunities.

Spark: At this stage if solutions begin to appear they are the result of the first two stages, and are often raw, sometimes naïve, and as Sawyer articulates, "The product of sparks that others have had" At this stage most work is still completely organic, but we see the benefits of students sharing all preliminary work with each other in gallery style settings and open, ongoing discussion.

Selection: This stage confirms for us, the teachers, that placing this project at the end of $2^{\text {nd }}$ year is paramount to its success. Our students, through previous studies and a collective program philosophy have learned to evaluate and use analysis to make informed decisions. Students are encouraged to examine, and if appropriate, discard ideas if they start to become contrived. One of the instructors for this project has often cautioned students not to "be too soon made glad"

Elaboration: In the final stage of synthesis, where work is to be viewed holistically, the students are required to incorporate all exploratory ideas, writings, and drawings. Here we see work become complex, multi-dimensional and deeply personal. In congruence with Sawyers description of this stage, we realize that the integration of many ideas into the " $X$ " requires personal reflection, social interaction, community, and the aforementioned sense of shared purpose.

The criteria are simple and extremely openEvaluation of the project is necessarily big picture and open-ended to be congruent with less constrained criteria. Evaluation is summative, based on assessing the whole experience in three different ways to determine a final grade. Echoing Stokes' arrangement of paired constraints as essential to creative development, The Creative Well promotes synthesis of spirit and object and precludes separation of creativity and work.

Teachers summarize the project, and their observations in a personal thank you to each student.

\section{Responses and research}

During the five years we have offered the Creative Well, we have been doing the kind of practical, classroom-based research that informs teaching. We habitually use student responses to gain insight into ways to foster creativity, and how to better work through the seeming paradox between creativity and pragmatic work.

Recently we asked students to write responses to the project for use in this paper. Some wrote as an immediate reaction to their work this year; others considered the project at a remove of 1-2 years; still others reflected as graduates now working in the industry. Although we encouraged students to write as critically as possible, all the responses were 
overwhelmingly positive. Not one student could find fault with the project. The most critical response came from a student who said that the project was not always fun in the moment.

Students who prefer to work in a linear logical fashion, while initially concerned and tentative, learned to trust process and themselves. One responded, "The Creative Well is what? I was so confused at the start. I am the type of student who likes to have a vision of what the final product will look like, but with The Creative Well, you can't. I learned to trust my creativity. This was the most difficult part for me. By letting my creativity take over, I thought the meaning behind my project was much stronger. All in all, The Creative Well helped me to rediscover that I am a creative person, something that I thought I lost in the past.”

Other students wrote about the thrill of finding, or rediscovering, voice and self.

"The Creative Well challenged me to make my life experiences a channel towards my creativity. The project encouraged me to reflect from many perspectives and it became clear that the creative self is constantly evolving. I learned to put value in my work, whether it may be a success or a failure, the experience is crucial to my evolution.”

What they learned surprised them. "The biggest thing that I learned was that it wasn't how creative and innovative I could be with an art piece but how to share what you want to share and be holistic with everything we did in class. I think that this project connects to fashion in a non-direct way to get us thinking creatively again.”

The responses never mentioned the product, and focused instead on learning, change, and process. In no discussion of the experience did students equate meaningful work and the grade received.

The results of The Creative Well project are immediate and long lasting. Students and teachers gain profound insight into the nature of creativity and the core value of creative endeavor in work and life. Over the five years that we have done this project we have learned as teachers that trust is key, that people will surprise you with their depth, humour, bravery and ingenuity.

In addition to these instances of personal, individual creative growth The Creative Well has nurtured the place of community in creative expression.

The creative community, bolstered by the exercises described earlier, is the ideal environment in which new contexts for creative work evolve. It is consistent with current scholarly approaches to the concept of happiness as it relates to creativity. Media professor David Gauntlett states that happiness (the preferred state for creative exploration) occurs within meaningful communal action and involvement. Such an approach also directly relates to the fashion industry and probably many others.
We have seen how this will affect not only the creative process for the students, but how they react to the processes of others. From the initial stages of the project and through the incubation period to the final holistic result, there have been profound changes in self-awareness based on the actions of the community.

An immigrant South Asian woman, whose final work was built on broken self-image, shared the story of her brother's gang activity and subsequent incarceration, and the resulting loss and shame within a family-based culture. She thanked the entire room for allowing her to be able to finally speak freely. Finding her voice in this project, and learning that she had support, prompted her to step outside her comfort zone and apply for international summer fashion internships.

A profoundly grade-driven student, with a penchant for perfectionism, surprised us from the beginning of the project with work that was exploratory, humourous and personal, qualities that had been notably lacking in any previous work. The unexpectedness of her process work was matched by an extremely moving piece that spoke not only to her troubled relationship with her mother, but nurture and abandonment. Her final work was a distinctly two-storied dollhouse, and she had removed the front so that all could see inside. The lower level epitomized a home of well-nourished love miniature cookies and pies on a checkered table. Miniscule flowerpots on well-tended sills - the entire room became a study in the cliché of a perfect family. Upstairs was a decrepit and forlorn attic with peeling wallpaper, the floor strewn with the detritus of time and neglect. A miniature chest sat isolated in the middle. Tiny letters written to an absent mother - a mother cruel in her inattention, and a child desperate for love-littered the floor. The finished work, exquisite in its craft and execution, resonated with every viewer who saw it. As teachers, we suddenly gained insight into this woman's rigid determination for the perfect A grade. Ironically, in taking down a wall, she had created some of her strongest work, and practiced some of the flexibility, use of metaphor and risk-taking commonly associated with creativity.

While some students choose to express the personal or emotional, others use the project to grapple with intellectual and social concerns. A woman who from her first class had grappled with the materialism of fashion and current culture, used key pieces of her process work, plus discarded and worn items, to create a public performance piece on one of our city's main shopping streets. She painted the lot gold, emailed a notice about "free treasure" and stood by her valuables for the afternoon, offering them at no cost to passers by. Another challenged the alienation of public space with intimate Post-It notes that reminded the reader of connection. 
Students have used their work as a springboard to comment on child soldiers and global networks of prostitution.

Only rarely does a student opt to express her work though traditional textiles, and even then the notion of fashion is transformed. This year a student combined her love of material with land art and created a video of a large circle of satin lying near a garden, a circle that swelled, sprouted fabric flowers, grew into something rich and strange. (This being Vancouver, rain was a key element.) Her final work consisted of her process, the slow moving video and the immediate sensation of the resulting garment.

Occasionally a student with a narrow view of career choices discovers she can be both technically proficient and an artist in her chosen career. "The Creative Well taught me that the foundation of fashion, as well as many other mediums, lie in art and your ability to communicate your ideas, " one wrote.

Students often opt to work across disciplines, in ways that might humble any teacher who perceives interdisciplinary concepts coming from the front of the room. Many projects combine sculpture, photography, video, poetry, music, song, or dance either as elements in an installation.

\section{Successes and challenges}

The Creative Well offers successes and presents a few unresolved challenges. Fashion students broaden their understanding of creativity and its rhythms, and learn methods of reconnecting with their core motivation. They learn they can start the unknown with trepidation and excitement and work through to a passionate sense of meaning, and that that skill can connect to future practice. Teachers learn the humbling lesson that the student in the classroom is a person of more depth, more resourcefulness, more flexibility, more courage, and more ability than assumed. Teachers also learn they need not be the sole class expert-many of our students are far more adept at embroidery than we. This provides teachers with a chance to model exploration and engagement for its own sake rather than to gain status through accomplishment.

Any project, no matter its success, contains challenges. Some may be resolvable, and some may not. Time is a major constraint. We structured this project to reflect the rough proportion of purely creative work involved in creating a successful line of clothing, and that means that occasionally students could have benefitted from just a bit more time in the construction of their final work. We have resolved this by regarding the final product as part of a whole, and at a prototype stage.

This year, the fifth for the project, saw more derivative work than before. Perhaps this is the result of common student knowledge about the project beforehand, reducing the element of discovery. Perhaps fewer of this year's students were open to risk-taking. Perhaps it is due to the tendency of teachers to take a jaded "seen it before" stance. We will be paying attention to this to see if it repeats.

Although this project is structured to touch on all of the multiple intelligences suggested by Gardner, thus opening the realm of creative response, teachers need to be vigilant about evaluating with a bias to their own preferred learning style. To counter that, we evaluate the whole, not the product, and evaluate in three ways. The first uses broad definitions of grade levels used in all our fashion design projects. The second is a slightly modified version of Jason Theodor's model, stressing "sharability" that connects to Csikszentmihalyi's insights into the social aspects of creative work. A few students have struggled with this aspect of creative communication, and recently we have used Huang's video "Solipsist" to generate discussion about visual communication and levels of meaning.

Theodor's evaluation system also contains two extremely useful terms that many teachers might consider adopting for a variety of projects. "Magic" addresses the quality of creativity to resist boundaries and "Bonus" covers what the teacher might never have imagined possible but immediately recognizes as valuable. Our third method, a continuum, is yet not all that we would want and we are investigating Sternbeg's categories of creativity as a possible solution. Evaluation ends, as it must in an educational institutional setting, focused on outcomes, with a grade, but to that we add a personal thank you and commentary about the whole work. It is important to remember that the grade is neither what students recall nor what they value in the project.

While we would hope that this project could be transferable to many disciplines and many contexts, there are very specific factors that are at play. The activities are probably open to radical change, dependent upon the discipline. However, teachers who do not work with cohorts of students, who do not build on previous curriculum, and who are nervous about discovery learning or unsure of their own creativity face challenges. Teachers who wish to build on this project are cautioned of the need to give up the certainty of the end result in terms of predictable product. However, our experience suggests, people are capable of profound creative change, this may be surmountable. It is unlikely that the Creative Well can be successful in an environment where all power and knowledge comes from the teacher, where there is a lack of faith in the process or where trust is lacking.

Writing in Creativity and Development, Sternberg suggests six required resources to promote creativity, all within the possibility of the classroom. Although 
he neglects any mention of physical action and creation, we agree with his basic premise. We build on his first two, intellectual abilities and knowledge, through TED talks, reflective writing and discussion. We open the class to various modes of thinking (and doing). We encourage intrinsic motivation through open-ended criteria and communal support. We promote the emergence of the personal. We create a social environment that supports possibility and an equally important physical environment that allows for multiple concurrent activities. We agree with Sternberg that these are necessary and connected, but would add to his list both actions and the essential component of trust.

We end our discussion of The Creative Well with two insights, one from a academic researcher deeply involved in the study of creativity, and one from a graduate, now employed and recalling her experience.

Sawyer, in Explaining Creativity, connects creativity to human potential in work and life, in health, and as an important aid to society and suggests its key role as a valuable educational asset for any teacher. Our students certainly make the holistic connections he discusses and we certainly gain in our growth as teachers.

A wonderfully cantankerous student initially complained vociferously about the project, and then surprised everyone with a final piece that had two components. Part one, a textural autobiography, told the story of her life as felt experience through everyday textiles formed into a wall piece. Part two, although she insisted she hated sketching and was poor in design, took those same textiles as the basis to create sketches for ritual garments. The dark velvet of the hanging, symbolizing her late teens, morphed into a mourning coat for a friend who had died. Asked five years later to recall the project, she replied, "I had forgotten all about the designs I did because the work that led to them was so much more compelling and personal to me. Textiles gave me the opportunity to tell the story of my life in a nonverbal, visceral way. It was an important reminder at a time when I felt particularly disconnected with fashion and perhaps needed it most - that the work I was doing could explore ideas larger than simply how we dress ourselves.“

\section{References}

Andreasen, Nancy C, The Creating Brain: The Neuroscience of Genius, Dana Press, New York, New York, 2005.

Csikszentmihalyi, Mihaly, Mihaly Csikzentmihalyi: Creativity, fulfillment and flow, TED, 2008, May 14, 2012.

Glennie, Evelyn, Evelyn Glennie shows how to listen, TED, 2007, Web, April 192012.
Gauntlett, David, Making is Connecting. The social meaning of creativity, from DIY to Youtube and Web 2.0, Polity Press, Cambridge, UK, 2011.

Gardner, Howard, Multiple intelligences: new horizons, BasicBooks, New York, New York, 2006.

Hargrove, R. (2011), 'Fostering creativity in the design studio: A framework towards effective pedagogical practices', Art, Design \& Communication in Higher Education 10: 1, pp. 7-31, doi: 10.1386/adch.10.1.7_1

Henry, Todd, The Accidental Creative: How to be Brilliant at a Moment's Notice, Portfolio/Penguin, New York, New York, 2011.

Huang, Andrew, Solipsist, vimeo, 2012, Web. April 5, 2012.

Jansen, Theo, Theo Jansen creates new creatures, TED, 2007, Web, April 192012.

JR, JR's TED Prize wish: use art to turn the world inside out, TED, 2011, Web, April 202012.

Kaufman, James C, and Sternberg, Robert J, Editors, The Cambridge Handbook of Creativity, Cambridge University Press, New York, New York, 2010.

Leonard, Dorothy and Swap, Walter, When Sparks Fly: Igniting Creativity in Groups, Harvard Business School Press, Boston, Massachusetts, 1999.

Loschek, Ingrid, When Clothes Become Fashion Design and Innovation Systems, Berg, New York, NY 2009.

Muniz, Vik, Vic Muniz makes art with wire, sugar, TED, 2007, Web, April 152012

Owens, David A, Creative People Must be Stopped: 6 Ways We Kill Innovation, Jossey-Bass, San Francisco, California, 2012.

Robinson, Andrew, Sudden Genius? The Gradual Path to Creative Breakthrough, Oxford University Press, New York, New York, 2010.

Robinson, Sir Ken, Changing Education Paradigms, RSAnimate, 2010, Web. 19 April, 2012.

Robinson, Sir Ken, Ken Robinson says schools kill creativity, TED, 2008, Web. 19 April, 2012.

Sawyer, R, Keith, et al, Creativity and Development, Oxford University Press, New York, New York, 2003.

Sawyer, R, Keith, Explaining Creativity: The Science of Human Innovation, Oxford University Press, New York, New York, 2006.

Stokes, Patricia D, Creativity From Constraints: The Psychology of Breakthrough, Springer Publishing Company, Inc., New York, New York, 2008.

Theodor, Jason, The Creative Method v2, Slide Share, 2010, Web, April 202012. 
Underwood, June, Sloppy Craft: It’s Getting Interesting, Art \& Perception a multi disciplinary dialog, 2009, Web. April 15, 2012.

Weston, Anthony, How to Re-Imagine the World

A pocket guide for practical visionaries, New Society Publishers, Gabriola Island, B.C. Canada 2007. 